\title{
A miRNA-101-3p/Bim axis as a determinant of serum deprivation-induced endothelial cell apoptosis
}

\author{
Ji-Hee Kim ${ }^{1}$, Dong-Keon Lee ${ }^{1}$, Joohwan Kim¹, Seunghwan Choi ${ }^{1}$, Wonjin Park', Kwon-Soo Ha', Tae-Hoon Kim¹, Jongseon Choe ${ }^{2}$, \\ Moo-Ho Won ${ }^{3}$, Young-Guen Kwon ${ }^{4}$ and Young-Myeong Kim ${ }^{\star, 1}$
}

Serum deprivation or withdrawal induces apoptosis in endothelial cells, resulting in endothelial cell dysfunction that is associated with cardiovascular disease. However, there is still limited information on the role of miRNA in serum deprivation-induced apoptosis. Here we found that serum deprivation increased caspase-dependent apoptosis through miRNA-101-3p downregulation, without altering expression of its host gene RNA $3^{\prime}$-terminal phosphate cyclase-like 1, which was highly correlated with suppressed expression levels of Dicer and Argonaute 2 (Ago2), indicating that miR-101-3p is post-transcriptionally elevated in serum-deprived conditions. The decreased miR-101-3p caused elevated Bim expression by targeting its $3^{\prime}$-untranslated region (3'-UTR). This resulted in activation of the intrinsic pathway of apoptosis via interaction with Bcl-2, decreased mitochondrial membrane potential, cytochrome $c$ release, mitochondrial reactive oxygen species (ROS) production, and caspase activation. These events were abrogated by miR-101-3p mimic and the proapoptotic Bim siRNA, which suggest a determinant role of the miR-101-3p/Bim axis in serum deprivation-induced apoptosis. The apoptosis induced by miR-101-3p-mediated Bim expression is mediated by both caspase-3 and -1 , which are activated by two distinct intrinsic mechanisms, cytochrome $c$ release and ROS-induced inflammasome activation, respectively. In other words, the antioxidant inhibited endothelial cell death mediated by caspase-1 that activated caspase-7, but not caspase-3. These findings provide mechanistic insight into a novel function of miR-101-3p in serum withdrawal-induced apoptosis triggered by activating two different intrinsic or mitochondrial apoptosis pathways, implicating miR-101-3p as a therapeutic target that limits endothelial cell death associated with vascular disorders. Cell Death and Disease (2017) 8, e2808; doi:10.1038/cddis.2017.219; published online 18 May 2017

Dysfunction of endothelial cells is directly associated with impaired vasorelaxation, increased inflammation, and increased migration and proliferation of smooth muscle cells. ${ }^{1}$ As a result, endothelial cell apoptosis, an important marker of vascular damage, is critically implicated in the pathogenesis of various cardiovascular diseases including atherosclerosis, hypertension, heart attack, and stroke. ${ }^{2}$

On the basis of mechanisms leading to distinct morphologies, cell death types are classified into apoptosis, autophagic cell death, necroptosis, pyroptosis, and necrosis. ${ }^{3,4}$ Among them, apoptosis is caused by two distinct signaling cascades, the extrinsic and intrinsic pathways. The extrinsic pathway triggered by death receptor activation is well characterized by identified intracellular signal cascades and sequential caspase activation. ${ }^{5}$ In contrast, the intrinsic pathway in response to cellular stresses, such as hypoxia, growth factor deprivation, and cytotoxic chemicals, activates caspase- 9 via the release of mitochondrial cytochrome $c .^{6}$ The mitochondrial pathway is primarily regulated by the relative levels and activity of the antiapoptotic and proapoptotic Bcl-2 family proteins. ${ }^{7}$ Although the proapoptotic genes can be upregulated in response to cytokine or growth factor withdrawal, ${ }^{8}$ the regulatory mechanism is largely unclear.
On the basis on their structures and functions, the members of the Bcl-2 superfamily are divided into prosurvival $\mathrm{Bcl}-2$, proapptotic Bax/Bak, and proapoptotic BH3-only family members. ${ }^{9}$ Among proapoptotic Bcl-2 members, Bim has an important role in initiating the mitochondria-dependent caspase- 3 activation that is responsible for endothelial cell death, which is a critical process in the pathogenesis of retinopathy. ${ }^{10}$ In contrast, the antiapoptotic $\mathrm{Bcl}-2$ proteins inhibit the intrinsic apoptotic pathway and also limit the caspase-1 activation that is involved in inflammation and pyroptosis ${ }^{11}$ by preventing the assembly of the NOD-like receptor containing pyrin domain 3 (NLRP3) inflammasome. ${ }^{12,13}$ Therefore, the balance between antiapoptotic and proapoptotic $\mathrm{Bcl}-2$ proteins is an important determinant in regulating endothelial dysfunction and apoptosis.

MicroRNAs (miRNAs) post-transcriptionally inhibit the expression of specific genes by binding to the $3^{\prime}$-untranslated region ( $3^{\prime}$-UTR) of target mRNAs. ${ }^{14}$ MiRNA plays an important role in the pathogenesis of cardiovascular diasease. ${ }^{15} \mathrm{~A}$ number of miRNAs have been shown to induce endothelial cell dysfunction or mitochondria-mediated apoptosis, contributing to cardiovascular diseases, ${ }^{16}$ In fact, several miRNAs, including miR-483-3p, miR-221, miR-222, and miR-17-5p, are

\footnotetext{
${ }^{1}$ Department of Molecular and Cellular Biochemistry, School of Medicine, Kangwon National University, Chuncheon, Gangwon-do 24341, Republic of Korea; ${ }^{2}$ Department of Immunology, School of Medicine, Kangwon National University, Chuncheon, Gangwon-do 24341, Republic of Korea; ${ }^{3}$ Department of Neurobiology, School of Medicine, Kangwon National University, Chuncheon, Gangwon-do 24341, Republic of Korea and ${ }^{4}$ Department of Biochemistry, College of Life Science and Biotechnology, Yonsei University, Seoul 03722, Republic of Korea

${ }^{*}$ Corresponding author: Y-M Kim, Department of Molecular and Cellular Biochemistry, College of Medicine, Kangwon National University, Chuncheon, Gangwon-Do 200701, Republic of Korea. Tel: +82-33-250-8831; Fax: +82-33-244-3286; E-mail: ymkim@kangwon.ac.kr.

Received 02.12.16; revised 04.4.17; accepted 13.4.17; Edited by G Raschellà
} 
overexpressed in tumor cells and contribute to antiapoptosis and drug resistance via downregulation of the proapoptotic Bcl-2 family members Puma, Bim, and Noxa. ${ }^{8,17-19}$ However, the involvement of miRNAs in the intrinsic apoptosis pathway that responds to cellular stresses by regulating proapoptotic $\mathrm{Bcl}-2$ gene expression is largely unknown.

In this study, we found that miRNA-101-3p (miR-101-3p) was downregulated in response to serum deprivation and induced endothelial cell apoptosis by targeting the $3^{\prime}$-UTR of Bim mRNA. These findings suggest that miR-101$3 p$ plays an important role in endothelial cell dysfunction and may be a therapeutic target for treating cardiovascular disorders.

\section{Results}

Serum withdrawal decreases miRNA-101-3p biogenesis. Because our previous study showed that hypoxia-responsive miR-101 regulates endothelial cell function related to angiogenesis and survival, ${ }^{20}$ we initially examined the effect of serum deprivation on miR-101-3p biogenesis in human umbilical vein endothelial cells (HUVECs). When cultured HUVECs with different serum concentrations $(5,1$, and $0 \%)$ for 8 and $16 \mathrm{~h}$, the precursor miR-101-3p level was inversely proportional to serum concentration, without changing the expression of its host gene RNA 3'-terminal phosphate cyclase-like 1 (RCL1); however, the level of mature miR-101$3 p$ decreased significantly (Figure 1a), and similar results were also observed in several tumor cell lines (Supplementary Figure S1a). These data suggest that serum depletion inhibits miR-101-3p biogenesis at the posttranscriptional level. Because Drosha, Dicer, and Argonaute 2 (Ago2) are crucial for post-transcriptional miRNA biogenesis, ${ }^{21}$ we determined these gene expression levels in serum-deprived HUVECs. Serum deprivation diminished the mRNA and protein levels of Dicer and Ago2, but not Drosha (Figures $1 b$ and $c$ ). These data suggest that serum deprivation inhibits miR-101-3p biogenesis, without changing RCL1 expression, by decreasing Dicer and Ago2 expression. Hawkins et al. proposed using next-generation sequencing that Dicer deletion can downregulate miR-181c expression, although the result was not reproducible by quantitative real-time PCR (qRT-PCR) analysis. ${ }^{22}$ However, our results showed that miRNA-181c level was unchanged in serum-deprived cells (Supplementary Figure S1b).

Serum deprivation elicits apoptosis by decreasing miRNA-101-3p biogenesis. Serum withdrawal decreased HUVEC survival with $\sim 50 \%$ cell death at $30 \mathrm{~h}$, compared with control cells incubated with $5 \%$ fetal bovine serum (FBS). The cell death was prevented in a dose-dependent manner by transfection with 50-100 nM miR-101-3p (Figures 2a and b), suggesting that miR-101-3p plays an important role in regulating serum deprivation-induced cell death. We next performed TUNEL assay to discriminate between apoptosis and other types of cell death. Serum deprivation resulted in a significant increase in the number of TUNEL-positive apoptotic cells compared with control cells, whose apoptotic effect was inhibited by miR-101-3p (Figures $2 c$ and $d$ ). Fluorescence-activated cell sorting (FACS) analysis using Annexin V-FITC/PI staining also confirmed that serum deprivation-induced apoptosis, which was inhibited by miR-101-3p (Figures $2 e$ and $f$ ). In addition, knockdown of Dicer and Ago2 decreased the miR-101-3p level and promoted endothelial cell apoptosis under serum-free or FBS-supplemented conditions, and this apoptotic cell death was inhibited by miR-101-3p (Supplementary Figures $\mathrm{S} 2 \mathrm{a}-\mathrm{e}$ and $\mathrm{S} 3 \mathrm{a}-\mathrm{e})$. This result suggests that serum deprivation induces endothelial cell apoptosis by suppressing miR-101-3p biogenesis via downregulation of Dicer and Ago2.

MiR-101-3p downregulated by serum deprivation triggers the intrinsic apoptosis pathway. We examined the role of miR-101-3p in serum deprivation-induced caspase activation. Endothelial cell death in serum-free condition was inhibited by the inhibitors of pan-caspase (z-VAD-fmk), caspase-7/3 (Ac-DEVD-cho), caspase-9 (Ac-LEHD-cho) or caspase-1 (Ac-YVAD-cho), but not by the caspase-8 inhibitor (AcIETD-cho) (Figure 3a). Moreover, the cell death was also abolished by transfection with miR-101-3p (Figure 3a). Similarly, z-VAD-fmk and Ac-YVAD-cho also inhibited serum deprivation-induced endothelial cell apoptosis (Figures $3 b$ and $c$ ). These results suggest that miR-101-3p downregulated by serum deprivation causes caspase-8-independent apoptosis. As expected, serum-deprived cells did not
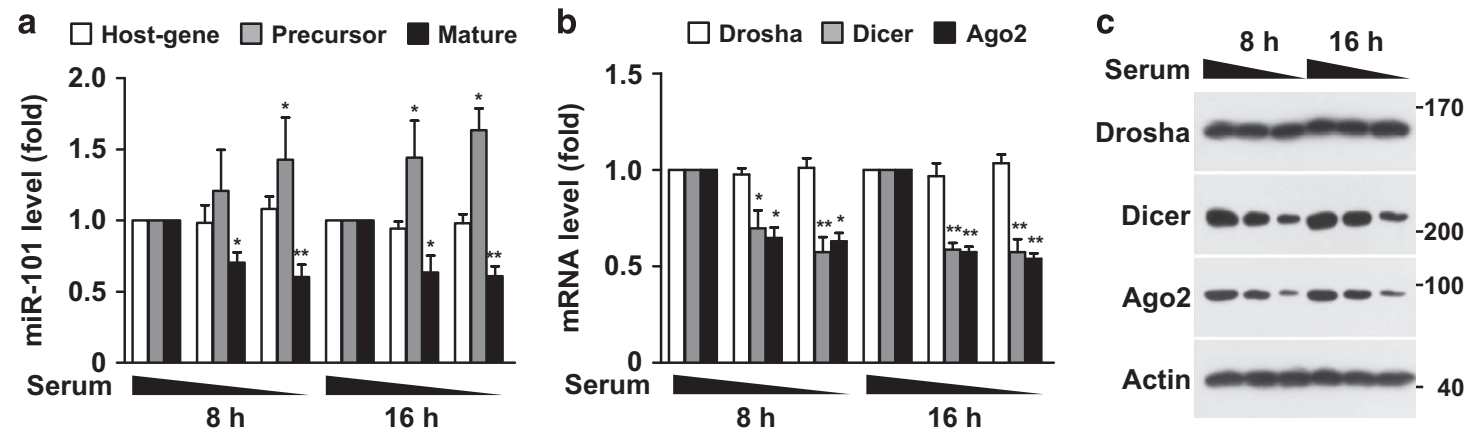

Figure 1 Serum deprivation decreases miR-101-3p biogenesis by downregulating Dicer and Ago2 expression. (a) HUVECs were cultured in 5, 1, and 0 FBS-supplemented M199 for 8 and $16 \mathrm{~h}$. Levels of RCL1 and precursor and mature miR-101 s were determined by qRT-PCR. (b and c) Under the same experimental conditions, Drosha, Dicer, and Ago2 mRNA and protein levels were determined by qRT-PCR and Western blot analysis. ${ }^{*} P<0.05$ and ${ }^{\star \star} P<0.01$ versus $5 \%$ serum 
a

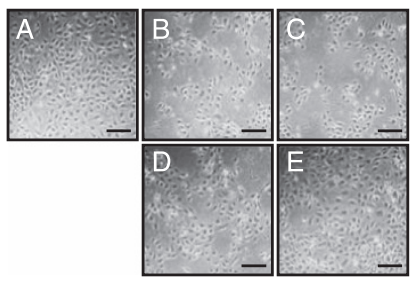

C

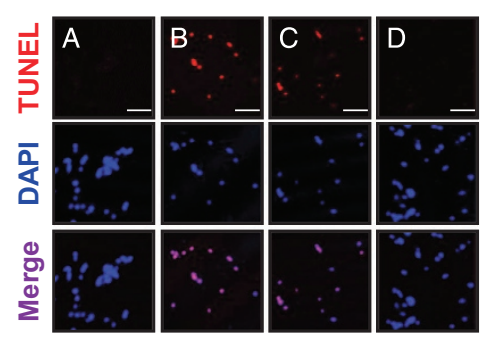

d

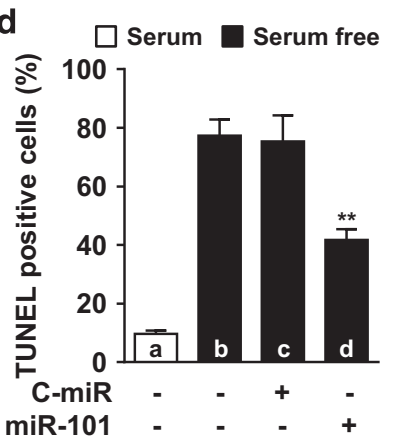

e

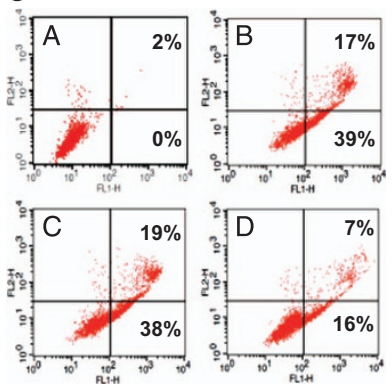

f

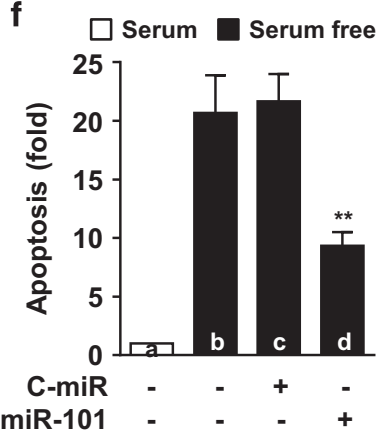

Figure 2 MiR-101-3p prevents serum deprivation-induced apoptosis. HUVECs were transfected with control miRNA (C-miR) or miRNA-101-3p mimic (miR-101) and cultured in serum-free or $5 \%$ FBS-supplemented media for $24 \mathrm{~h}$ (TUNEL and FACS analysis) or $30 \mathrm{~h}$ (cell viability). (a and $\mathbf{b}$ ) Cell viability was evaluated by microscopy (a) and MTT assay (b). Scale bars, $50 \mu \mathrm{m}$. A: $5 \%$ FBS, B: serum-free, C: serum-free+100 nM C-miR, D: serum-free+50 nM miR-101, and E: serum-free+100 nM miR-101. (c) Apoptosis was determined by TUNEL assay, and nuclei were also stained with DAPI. Scale bars, $50 \mu \mathrm{m}$. A: 5\% FBS, B: serum-free, C: serum-free+C-miR, D: serum-free+100 nM miR-101. (d) Quantitation of TUNEL-positive cells. (e) Cells were stained with Annexin V and PI and analyzed by FACS. A: 5\% FBS, B: serum-free, C: serum-free+100 nM C-miR, D: serumfree+100 nM miR-101. (f) Quantitation of cells stained with both Annexin V and PI. ${ }^{*} P<0.05$ and ${ }^{* *} P<0.01$ versus cells transfected with $C$-miR in serum-free media

increase caspase-8-like protease (IETDase) activity, proteolytic caspase-8 activation, and its biological substrate Bid cleavage, and these events were not affected by miR-101-3p (Figures 3d and e). Furthermore, miR-101-3p overexpression inhibited the serum withdrawal-induced increases in caspase-9 (LEHDase)-like and caspase-7/3 (DEVDase)-like activities, as did z-VAD-fmk, Ac-LEHD-cho, and Ac-DEVDcho (Figures $3 f$ and g). Similarly, miR-101-3p inhibited proteolytic caspases-9/3 activation in serum-deprived cells (Figure 3h). In contrast, knockdown of Dicer or Ago2, an upstream mediator of miR-101-3p biogenesis, increased caspase-9-like (LEHDase), caspase-7/3-like (DEVDase), and caspase-1-like (YVADase) activities independent of serum status, and these enzyme activities were significantly reduced by miR-101-3p (Supplementary Figures S2f and S3f). These data suggest that downregulated miR-101-3p plays an important role in triggering the caspase-8independent or intrinsic apoptosis pathway that is evoked by serum deprivation.

Serum deprivation increases Bim expression via decreased miR-101-3p biogenesis. Because serum or trophic factor deprivation induces endothelial cell apoptosis, ${ }^{23}$ we predicted the highly reliable apoptosisrelated genes of miR-101-3p using TargetScan, microRNA. org, and miRDB. As a result, we selected Bim as a potential target gene of miR-101-3p given that its target site is conserved among mammals and three Bim isoforms including extra-long, long, and short forms (Supplementary Figure $\mathrm{S} 4 \mathrm{a}-\mathrm{c}$ ). We further verified Bim as a bona fide target of miR-101-3p through the significant increases in Bim mRNA and protein levels as a result of serum deprivation (Figures $4 a$ and b). In addition, serum-deprived cells increased Bim mRNA $3^{\prime}$-UTR but not its mutant activity, and this increase was suppressed by transfection of miR-101-3p, whose suppressive effect was recovered by antagomiR-101-3p (Figure 4c). Similar results were also observed in serumsupplemented cells transfected with miR-101-3p or anatogomiR-101-3p (Figure 4c). As expected, elevated Bim protein levels in the serum-deprived cells were reduced to the control levels by miR-101-3p overexpression (Figure 4d). In addition, Dicer or Ago2 knockdown increased Bim mRNA levels in HUVECs independent of serum status (Supplementary Figures S2g and S3g). We also confirmed that treatment with anatagomiR-101-3p increased Bim expression and apoptotic cell death in serum-supplemented cells (Supplementary Figure $\mathrm{S} 5 \mathrm{a}-\mathrm{c}$ ). These results suggest that serum deprivation increases Bim expression via downregulation of miR-101-3p, which directly targets the $3^{\prime}-U T R$ of Bim mRNA.

The serum deprivation-induced intrinsic apoptosis pathway is mediated by the miR-101-3p/Bim axis. Bim, a proapoptotic $\mathrm{BH} 3$-only member, activates the mitochondrial pathway of apoptosis by interacting with $\mathrm{Bcl}-2 .{ }^{24} \mathrm{We}$ examined whether the miR-101-3p/Bim axis would be 

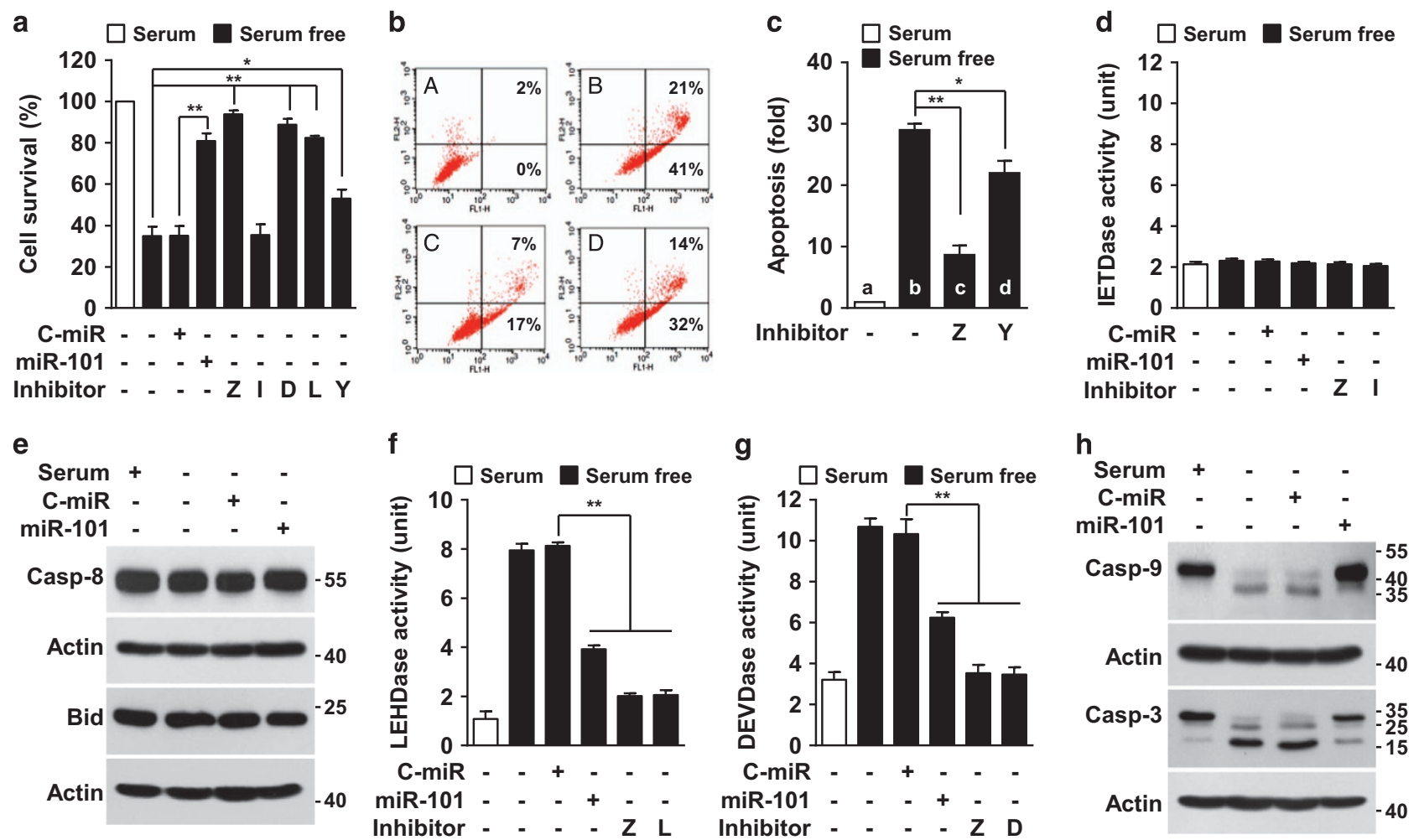

Figure 3 MiR-101-3p inhibits serum deprivation-induced caspase activation and apoptosis. Cells were transfected with C-miR or miR-101-3p and cultured with or without $50 \mu \mathrm{M}$ of Z-VAD-fmk (Z), Ac-IETD-cho (I), Ac-DEVD-cho (D), Ac-LEHD-cho (L), or Ac-YVAD-cho (Y) in serum-free or 5\% FBS-supplemented media for $24 \mathrm{~h}$ (FACS and caspase assay) or $30 \mathrm{~h}$ (MTT assay). (a) Cell viability was measured by MTT assay. (b and $\mathbf{c}$ ) Apoptosis was determined serum-deprived HUVECs by FACS analysis. A: $5 \%$ FBS, B: serum-free, C: serum-free+Z-VAD-fmk, D: serum-free+Ac-YVAD-cho. (d, $\mathbf{f}$, and $\mathbf{g}$ ) IETDase, LEHDase, and DEVDase activity were determined in cell lysates by colorimetric assay. (e) Caspase-8 and Bid cleavage were determined in cell lysates by western blot analysis. (h) Caspases- $9 / 3$ activation was determined by Western blot analysis. ${ }^{*} P<0.05$ and ${ }^{*} P<0.01$

involved in apoptosis induced by serum deprivation. Apoptotic cell death of serum-deprived endothelial cells was significantly inhibited by transfection with miR-101-3p or Bim siRNA (Figures $5 a$ and b). Both transfections effectively blocked the serum deprivation-induced increases in Bim mRNA and protein levels, but not the expression of Bax, an internal control gene that is not targeted by miR-101$3 p$ (Figures $5 c$ and $d$ ). Moreover, miR-101-3p overexpression and Bim knockdown significantly inhibited the serum deprivation-mediated increases in caspases-9/3-like protease activity (Figures $5 \mathrm{e}$ and $\mathrm{f}$ ). Because Bim is a trigger of the intrinsic apoptosis pathway, ${ }^{5}$ we examined the role of miR-101-3p in the mitochondrial events of apoptosis. Serum withdrawal increased the formation of the Bcl-2/Bim complex through upregulation of Bim expression, resulting in a significant reduction of $\mathrm{Bcl}-2 / \mathrm{Bax}$ interaction, and these events were inhibited by transfection with miR-101-3p or Bim siRNA (Figure 5g). Furthermore, miR-101-3p overexpression or Bim knockdown prevented the loss of mitochondrial membrane potential (MMP) and cytochrome $c$ release from mitochondria in serum-deprived cells (Figures $5 \mathrm{~h}$ and i). These data suggest that serum deprivation triggers the intrinsic apoptosis pathway via the miR-1013p/Bim axis responsible for cytochrome $c$ release from mitochondria.
Serum deprivation-induced miR-101-3p/Bim axis causes mitochondria-dependent caspase-1 activation. Mitochondria-derived reactive oxygen species (ROS) stimulate the formation of the NLRP3 inflammasome, ${ }^{12}$ leading to caspase-1 activation that induces apoptosis. ${ }^{25}$ We found in this study that serum deprivation significantly increased mitochondrial ROS production, which was inhibited by transfection with miR-101-3p or Bim siRNA (Figures 6a and b). Serum withdrawal stimulated inflammasome assembly through the interaction of a caspase activation and recruitment domain (ASC) with NLRP3 and caspase-1, and this complex formation was decreased by transfection with miR-101-3p or Bim siRNA (Figure 6c). Under the same experimental condition, the serum deprivation-induced increases in YVADase activity and proteolytic caspase-1 activation were suppressed by miRNA-101-3p or Bim siRNA (Figures $6 \mathrm{~d}$ and $\mathrm{e}$ ). Since caspase- 1 cleaves prolL-1 $\beta$ and prolL-18 to their mature forms, we next examined whether serum deprivation would regulate expression and maturation of these cytokines. Serum deprivation did not increase detectable levels of IL-1 $\beta$ and IL-18 expression or IL- $1 \beta$ maturation (Figure 6f). These data suggest that the miR-101$3 p / B i m$ axis promotes mitochondrial ROS generation, which stimulates inflammasome assembly and caspase- 1 activation, but not IL-1 $\beta$ and IL-18 expression and maturation, in serum-deprived endothelial cells. 


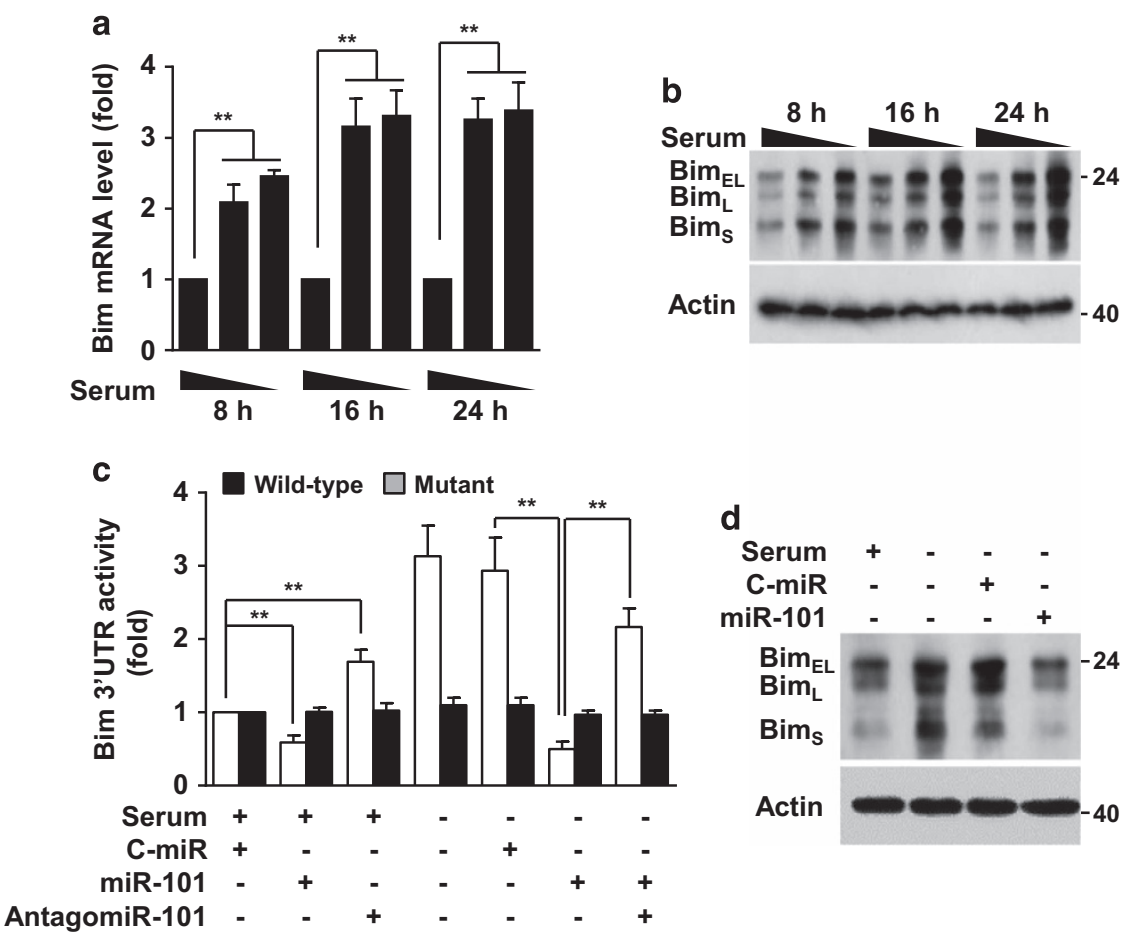

Figure 4 Serum deprivation increases the expression of Bim, a target of miR-101-3p. Cells were cultured in 5,1 , and $0 \%$ FBS-supplemented media in the presence of $50 \mu \mathrm{M}$ Z-VAD-fmk for $16 \mathrm{~h}$. (a and $\mathbf{b})$ Bim mRNA and protein levels were determined at different time points by qRT-PCR and western blot analysis. (c and $\mathbf{d})$ Cells transfected with C-miR, miRNA-101, antagomiR-101-3p or psiCHECK-2/Bim 3'-UTR (wild-type or mutant) were cultured in 5\% FBS-supplemented or serum-free media containing $50 \mu$ M Z-VADfmk for 16 h. (c) Bim 3'-UTR activity was determined using a dual-luciferase reporter assay system. (d) Bim protein level was determined by western blot analysis. Bim $\mathrm{EL}_{\mathrm{L}}$, Bim $\mathrm{L}$, and Bims indicate extra long, long, and short forms of Bim. ${ }^{* \star} P<0.01$

Antioxidants inhibits serum deprivation induces caspase-1-mediated apoptosis. We examined using antioxidants whether mitochondrial ROS production is an important factor for serum deprivation-induced caspase-1 activation and apoptosis. As shown by transfection with miR-101-3p or Bim siRNA (Figures $6 a$ and b), treatment with Trolox (antioxidant) or Mito-TEMPO (mitochondria-targeted antioxidant) also effectively inhibited mitochondrial ROS generation in serum-deprived HUVECs (Figures 7a and b). Similarly, both antioxidants suppressed serum starvationinduced assembly of the NLRP3 inflammation, which consists of NLRP3, ASC, and caspase-1 (Figure 7c). Moreover, the antioxidants significantly inhibited the serum-deprived increases in YVADase activity and proteolytic caspase- 1 activation (Figures $7 d$ and e). These results suggest that ROS generated from mitochondria by the miR-101-3p/Bim pathway stimulates inflammasomemediated caspase-1 activation. Further examination of whether mitochondrial ROS is involved in endothelial cell apoptosis via caspase- 1 activation showed that the antioxidants Trolox and Mito-TEMPO protected cells from serum deprivation-induced apoptosis, and the protective effect of Mito-TEMPO was further increased by co-treatment with Ac-DEVD-Cho, but not with Ac-YVAD-Cho (Figure 7f), suggesting that caspase-1 activation by ROS-mediated formation of inflammasome promotes apoptosis via activation of DEVDase. Thus, the miR-101-3p/Bim axis plays a key role in serum deprivation-induced apoptosis by promoting inflammasome assembly and caspase- 1 activation via mitochondrial ROS production. However, the mitochondrial ROS production was not significantly inhibited by caspase inhibitors, Z-VAD-fmk, Ac-YVAD-cho, Ac-LEHD-cho or Ac-DEVD-cho (Supplementary Figure $S 6 a-c$ ), indicating that caspases are not involved in serum deprivation-induced ROS generation.

Inflammasome-mediated caspase-1 activity induces apoptosis by activating caspase-7, but not caspase-3. Since caspase-1 induces pyroptosis by activating executive caspases, like DEVDase, ${ }^{26}$ we examined whether caspase-1 would activate other caspases in serum-deprived HUVECs. LEHDase activity increased by serum starvation was inhibited by miR-101-3p, but not Ac-YVAD-cho (Figure 8a), whereas DEVDase activity was partially inhibited by both miR-101-3p and Ac-YVAD-cho (Figure 8b), suggesting that caspase-1 stimulates DEVDase activity. We next examined the effect of ASC (an essential component of inflammasome complex) on caspase-7/3-like (DEVDase) activity and cell death using ASC siRNA. ASC knockdown inhibited YVADase and DEVDase activity, but not that of LEHDase, in serum-deprived cells (Figures $8 c$ and $d$ ). Because the executioner caspase-7/3 cleave the same substrate Ac-DEVD-pNA used in this study, ${ }^{27}$ we further determined which caspases could be activated by caspase-1. Both caspases were activated by serum starvation, whereas only caspase-7 activation was partially inhibited by ASC siRNA 


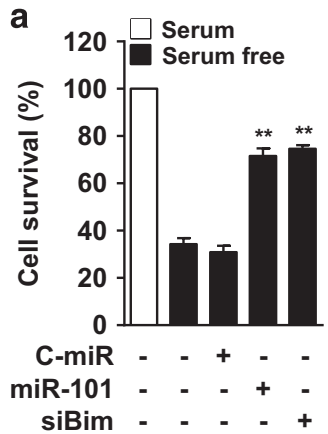

f

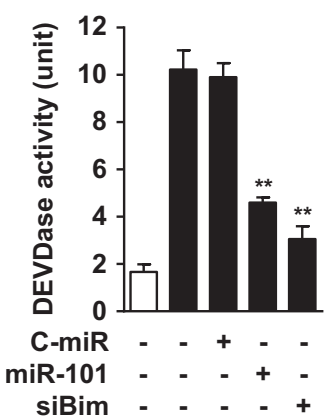

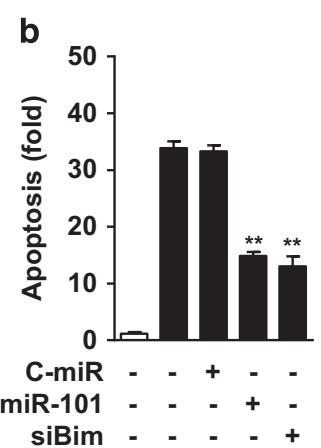

g

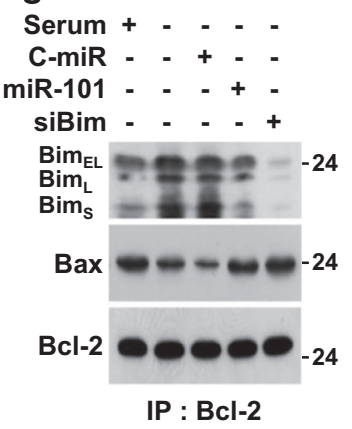

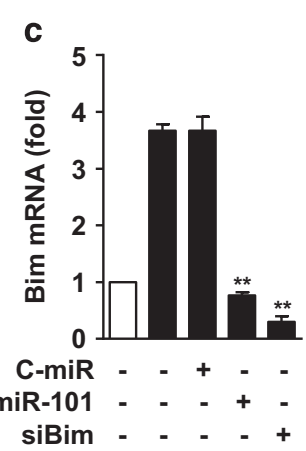

h

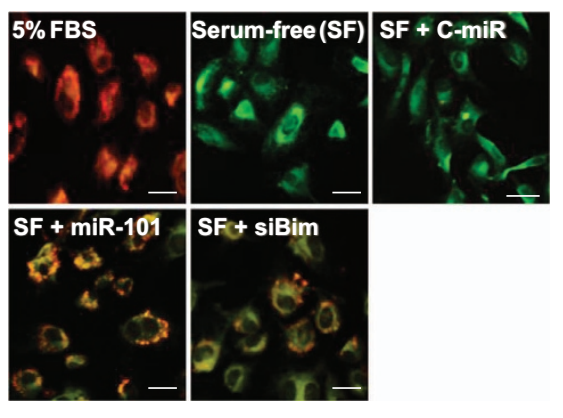

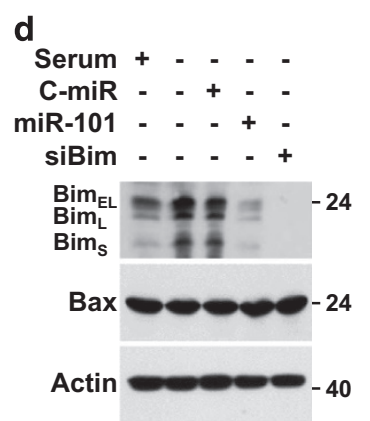

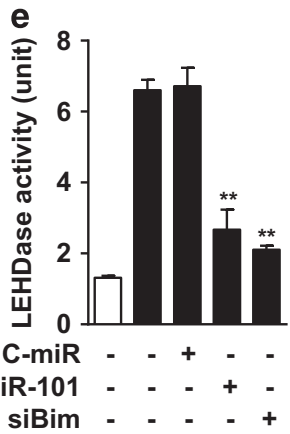

i

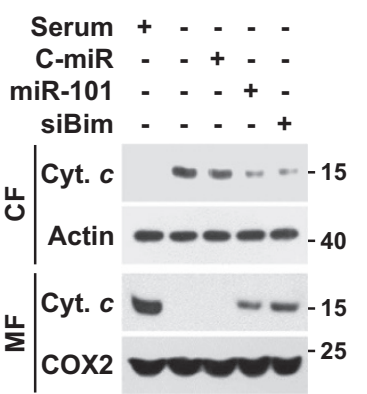

Figure 5 MiR-101-3p regulates serum deprivation-induced intrinsic apoptosis by inhibiting Bim expression. Cells were transfected with C-miR, miR-101 or Bim siRNA (siBim), followed by culture in serum-free or 5\% FBS-supplemented media for $12 \mathrm{~h}$ (IP and MMP), $16 \mathrm{~h}$ (gene and protein expression), $24 \mathrm{~h}$ (FACS and caspase assay) or $30 \mathrm{~h}$ (cell viability). (a) Cell viability was determined by MTT assay. (b) Apoptosis was evaluated by FACS analysis after staining with Annexin V and PI. (c) Bim mRNA level was determined by qRT-PCR. (d) Bim and Bax protein levels were determined by western blotting. (e and f) LEHDase and DEVDase activity were determined in cell lysates by colourimetric assay. (g) Cell lysates were immunoprecipitated with an antibody for Bcl-2. Interaction of Bcl-2 and Bim or Bax was determined by western blotting. (h) MMP was analyzed by confocal microscopy using a JC-1 dye. Scale bars, $20 \mu \mathrm{m}$. (i) Cytochrome clevels were determined in the cytosolic (CF) and mitochondrial fractions (MF) by Western blot analysis. COX2; Cytochrome $c$ oxidase subunit II. ${ }^{*} P<0.01$ versus cells transfected with $\mathrm{C}$-miR in serum-free media

and Ac-YVAD-cho (Figure 8e). As expected, ASC knockdown protected the cells from serum deprivation-induced cell death (Figure 8f). These results suggest that inflammasomemediated caspase-1 activity induces pyroptosis by activating caspase-7, but not caspase-3, in serum-deprived endothelial cells.

\section{Discussion}

MiRNA synthesis is a two-step sequential process following RNA pol II/III-dependent transcription of pri-miRNA, with both nuclear and cytoplasmic cleavages to pre-miRNA and mature miRNA by Drosha and Dicer, respectively. ${ }^{21}$ In fact, serum deprivation has been shown to induce endothelial cell apoptosis via caspase-3 activation by decreasing Dicer expression, and these unfavorable phenomena were abrogated by Dicer overexpression, ${ }^{28}$ indicating that miRNAs are critically involved in serum deprivation-induced apoptosis. Moreover, genetic deletion of Dicer upregulated the proapoptotic target gene Bim, reflecting apoptotic cell death. ${ }^{22}$ These data suggest that serum deprivation promotes apoptosis by decreasing Dicer expression, probably due to decreased biogenesis of miRNAs that target apoptosis-associated genes. Here we found that serum withdrawal decreased Dicer expression, thereby leading to increased susceptibility to apoptosis through downregulation of miR-101-3p, which targets the 3' UTR of Bim mRNA.
The mature miRNA duplex generated by Dicer is loaded into the RNA-induced silencing complex (RISC, consisting of Dicer, TRBP, and Ago2) and generates a single-stranded mature miRNA by cleaving the passenger strand. Activated RISC binds to the target mRNA through complementary base-pairing between the guide strand and the $3^{\prime}$-UTR of the target, resulting in the cleavage of target mRNA and posttranscriptional gene silencing. ${ }^{29}$ Among the components of RISC, Ago2 is critically involved in silencing the target gene. Ago2 is downregulated in serum-deprived HeLa cells, although an exact mechanism has not been elucidated. ${ }^{30}$ Similarly, we found that serum withdrawal suppressed Ago2 expression in HUVECs and decreased the expression of the miR-101-3p target gene Bim. Our data also showed that either Dicer or Ago2 knockdown induced apoptosis via increased Bim expression by inhibiting miR-101-3p biogenesis. That is, serum starvation upregulates Bim expression via miR-101-3p downregulation by decreasing Dicer and Ago2 expression.

It was shown that miR-101 can sensitize tumor cells chemotherapeutic drug-induced apoptosis by indirectly upregulating Bim expression in an EZH2-dependent epigenetic control manner. ${ }^{27}$ However, we demonstrated that miR-101$3 p$ directly targets the $3^{\prime}-$ UTR of Bim mRNA, resulting in increased Bim expression in serum-deprived endothelial cells. It is also possible that miR-101 regulates expression of cell survival genes, such as Mcl-1 and AMPK, by targeting their 3'-UTRs. ${ }^{31,32}$ These target genes have the same canonical 
a

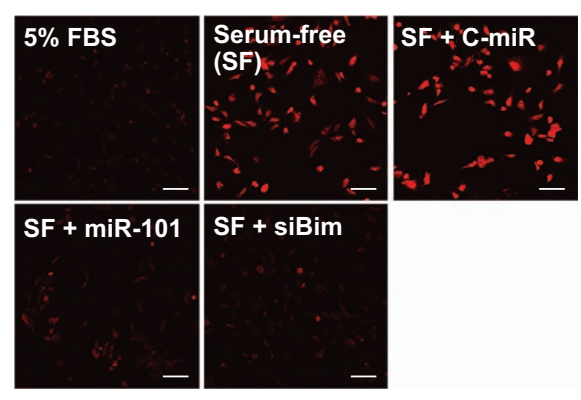

d

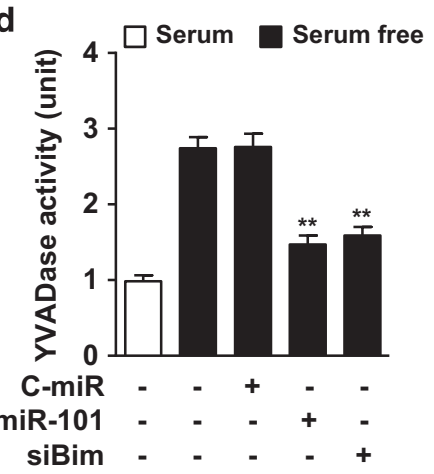

b

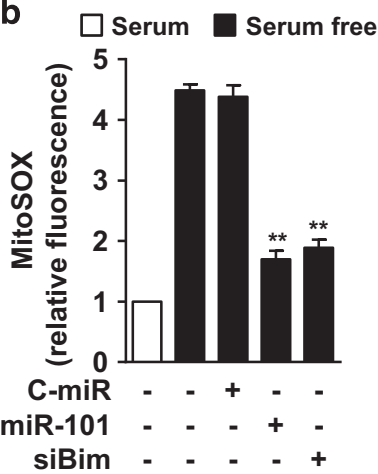

e

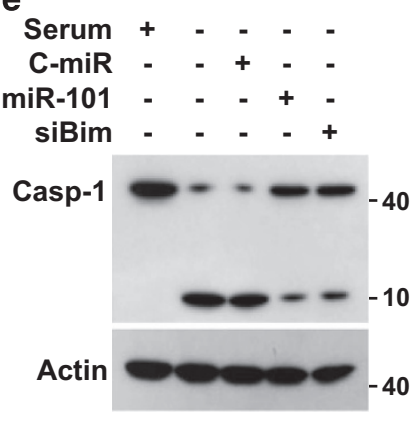

C

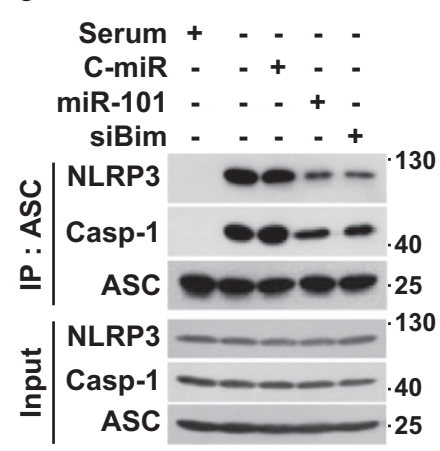

f

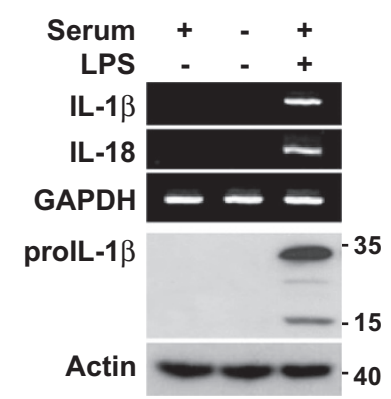

Figure 6 MiR-101-3p blocks serum deprivation-induced mitochondrial ROS production and caspase-1 activation. Cells were transfected with C-miR, miR-101 or siBim, followed by culture in serum-free or 5\% FBS-supplemented media for $12 \mathrm{~h}$ (ROS assay and IP) or $24 \mathrm{~h}$ (caspase assay). (a) Mitochondrial ROS generation was identified by confocal microscopy using MitoSOX. Scale bars, $50 \mu \mathrm{m}$. (b) Relative fluorescence intensity was quantitated by Image $\mathrm{J}$ software. (c) Cell lysates were immunoprecipitated with an antibody for ASC. Interaction among NLRP3, caspase-1, and ASC was determined by Western blot analysis. (d) YVADase activity was determined in cell lysates by colorimetric assay. (e) Proteolytic caspase-1 activation was determined by Western blotting. (f) Cells were cultured in serum-free or $5 \%$ FBS-supplemented media for $16 \mathrm{~h}$. Levels of IL-1 $\beta$ and IL-18 were determined by RT-PCR and Western blotting. LPS $(100 \mathrm{ng} / \mathrm{ml})$ was used as a positive control. ${ }^{* *} P<0.01$ versus cells transfected with C-miR in serum-free media

seed-matched sequences of $8 \mathrm{mer}$ (Supplementary Figure S7a), leading to similar responses to miR-101-3p overexpression (Supplementary Figure S7b and c). However, Bim expression was higher than ther other genes in serumdeprived cells (Supplementary Figure S7d-f). This phenomenon may have occurred via the cooperative action of miR-101-3p with other miRNAs or factors that are responded by serum deprivation or Dicer deletion. ${ }^{33-37}$ Therefore, further study is needed to understand the interaction between miR-101-3p and Bim expression in serum-derived endothelial cells.

In contrast to the antiapoptotic function of decreased miR-101-3p level in tumor cells, ${ }^{31,38}$ its downregulation promoted apoptosis in mouse primary cardiac fibroblasts exposed to hypoxia. ${ }^{39}$ Similarly, miR-101 is downregulated in Dicer-knockout mice and increased apoptosis via elevation of Bim expression. ${ }^{22}$ Consistent with this finding, our data showed that serum deprivation-induced endothelial apoptosis through downregulation of miR-101-3p, which targets Bim. All of these evidences suggests that miR-101-3p has a distinct cellular function, such as tumor-suppressive (e.g., apoptotic) versus antiapoptotic (survival) activity in tumor cells and normal cardiovascular cells, respectively. There are two possible explanations for this phenomenon. First, miR-101-3p may differently regulate the target gene expression in tumor and normal cells, as shown in a distinct gene expression pattern at the transcriptional level in a cell type (or cell differentiation stage)-specific manner. Another explanation may be related to the characteristics of the miRNA-target gene network that a miRNA targets multiple genes in a sequence-specific, but not gene-specific manner.

Apoptosis is mediated by two central pathways, an extrinsic pathway involving cell surface receptors and an intrinsic pathway using mitochondria. ${ }^{40}$ Activation of death receptors by their respective ligands induces sequential intracellular signal events, such as caspase-8 activation, Bid cleavage, mitochondrial cytochrome $c$ release, and caspases- 9 activation, resulting in proteolytic cleavage of the executioner caspase-7/3 and subsequent induction of apoptosis. On the other hand, intrinsic death stimuli induce cytochrome c-mediated apoptotic signal cascades, without caspase-8 activation. $^{41}$ We observed that serum-deprived HUVECs induced increased mitochondrial cytochrome $c$ release and caspases-9/7/3 activation, without caspase-8-mediated cleavage of Bid, suggesting that serum deprivation induces endothelial cell apoptosis via the intrinsic pathway. ${ }^{42}$ Moreover, endothelial cell apoptosis induced by serum deprivation was effectively inhibited by a miR-101-3p mimic, but not by a caspase- 8 inhibitor. These data indicate that miR-101-3p plays an important mediator role in mitochondria-dependent intrinsic apoptosis in serum-deprived endothelial cells. 
a

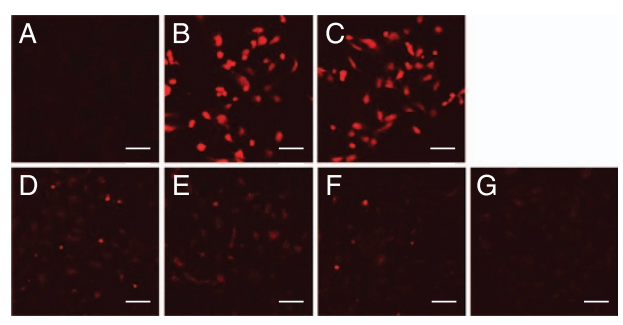

b

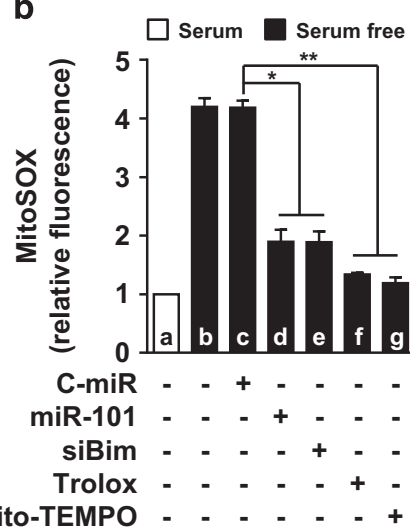

C

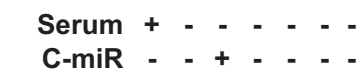

miR-101 - - + - -

siBim - - - + - -

Trolox - - - - + -

mito-TEMPO - - - - - - +

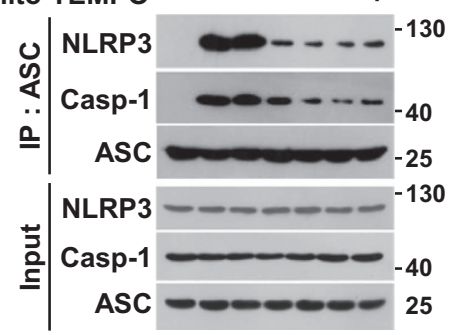

f $120 \square$ Serum $\square$ Serum free

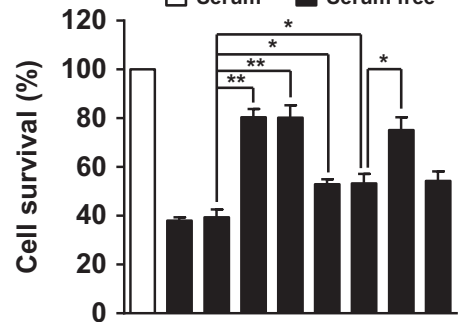

C-miR - - + - - - - - -

miR-101 - - - + - - - - -

siBim - - - + - - -

Trolox - - - - + + - -

mito-TEMPO - - - - - - + + +

Inhibitor - - - - - - D Y

Figure 7 MiR-101-3p blocks serum deprivation-induced mitochondrial ROS production, NLRP3 inflammasome activation, and caspase-1 activation. Cells were transfected with C-miR, miR-101 or siBim, followed by treatment with Trolox, Mito-TEMPO, Ac-DEVD-cho (D) or Ac-YVAD-cho (Y) in serum-free media for $12 \mathrm{~h}$ (ROS assay and IP), $24 \mathrm{~h}$ (caspase assay) or $30 \mathrm{~h}$ (MTT assay). (a) Mitochondrial ROS generation was identified by MitoSOX-based confocal microscopy. Scale bars, $50 \mu \mathrm{m}$. A: $5 \%$ FBS, B: serum-free, C: serum-free+100 nM C-miR, D: serum-free+100 nM miR-101, E: serum-free+100 nM siBim, f: serum-free+10 $\mu \mathrm{M}$ Trolox, g: serum-free+10 $\mu \mathrm{M}$ mito-TEMPO. (b) Fluorescence intensity was determined by Image J software. (c) NLRP3 inflammasome activation was determined by Western blotting following IP. YVADase activity (d) and proteolytic caspase-1 activation (e) were determined in cell lysates by colourimetric assay and Western blot analysis. (f) Cell viability was also determined by MTT assay. ${ }^{\star} P<0.05$ and ${ }^{*} P<0.01$

The intrinsic apoptosis pathway is usually regulated by a balance between proapoptotic and prosurvival $\mathrm{Bcl}-2$ family proteins proteins. Among proapoptotic $\mathrm{Bcl}-2$ proteins, Bim interacts with prosurvival $\mathrm{Bcl}-2$ members including $\mathrm{Bcl}-2$ and $\mathrm{Bcl}-\mathrm{xL}$ to allow the release of the $\mathrm{BH}$-only proapoptotic Bax and Bak proteins from their heterodimeric complexes. ${ }^{24}$ The release of these proteins in turn drives the apoptogenic cytochrome $c$ release from the mitochondria, resulting in the activation of caspase-7/3 that execute apoptosis. Alternatively, Bim can directly activate Bax or Bak through interaction with them; thus, Bim is an important component for initiating the intrinsic apoptosis pathway. In accordance with a previous study, ${ }^{43}$ we found that Bim plays a central role in apoptosis in response to serum deprivation. Taken in combination with recent findings, it would appear that Bim is an important mediator of mitochondria-dependent endothelial cell apoptosis induced by serum or growth factor deprivation. ${ }^{25,43}$ However, the mechanism linked to how Bim expression is regulated in response to serum starvation has not been clearly defined. A recent study showed that serum withdrawal induced endothelial apoptosis by downregulating miR-17-5p, which increases Bim expression by targeting its $3^{\prime}-$ UTR. ${ }^{33,36}$
In addition, Dicer ablation increases cell death by downregulating miR-20 and miR-302, which inhibit Bim expression by targeting its $3^{\prime}-\mathrm{UTR}^{37}$ indicating that Bim is upregulated in a miRNA-dependent manner. It suggests that upregulation of Bim in serum-deprived endothelial cells can be cooperatively induced by several miRNAs, including miR-101-3p.

Dicer is downregulated in HUVECs and fibroblasts by serum starvation, and this effect is abolished by angiogenic stimuli, such as vascular endothelial cell growth factor (VEGF) or sphingosine-1-phosphate (S1P), but not basic fibroblast growth factor and lysophosphatidic aid. ${ }^{28}$ This suggests that VEGF and S1P are important serum components for maintaining Dicer expression and preventing apoptosis. Indeed, inhibiting VEGF activity induces endothelial cell apoptosis by increasing Bim expression and vice versa. ${ }^{44}$ In this study, we demonstrated that serum deprivation increased Bim expression via the downregulated biogenesis of miR-101-3p that targets the $3^{\prime}$-UTR of Bim mRNA, resulting in the increases in Bax activity and mitochondria-dependent apoptosis. In addition, miR-101-3p biogenesis was also found to be decreased by downregulation of Dicer in serum-deprived HUVECs, although the regulatory mechanism has not been clarified as yet. 


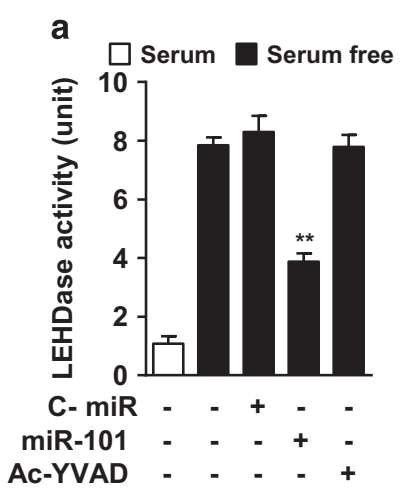

d

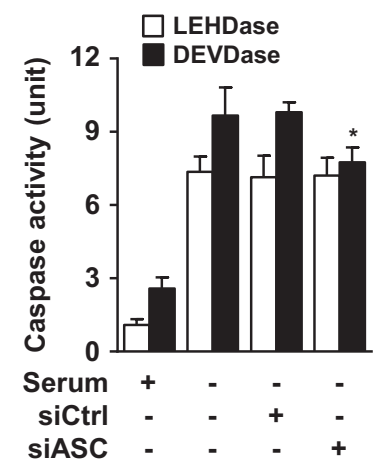

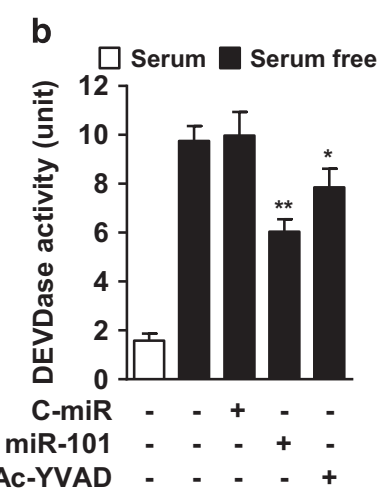

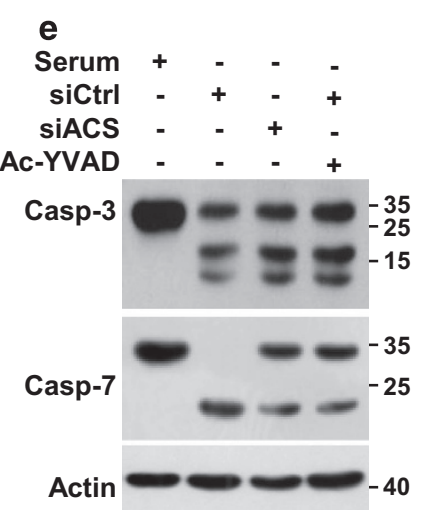

c

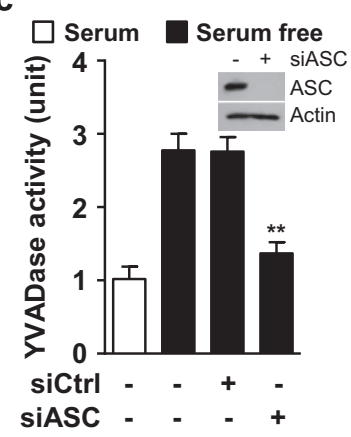

f

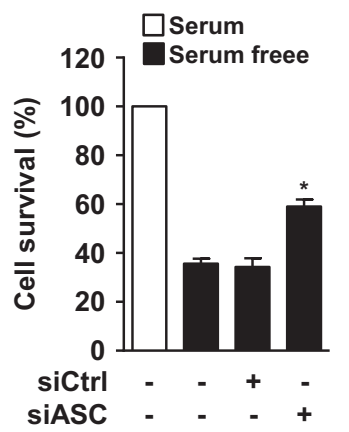

Figure 8 Caspase-1 induces serum deprivation-induced apoptosis by increasing caspase-7 activation. Cells were transfected with C-miR, miR-101, control siRNA (siCtrl) or ASC siRNA (siASC), followed by treatment with Ac-YVAD-cho in serum-free media for $24 \mathrm{~h}$ (caspase assay) or $30 \mathrm{~h}$ (cell viability). (a - d) Caspase activity was determined in cell lysates by colorimetric assay. (e) Caspases-3/7 activation was determined by Western blot analysis. (f) Cell viability was evaluated by MTTassay. ${ }^{*} P<0.05$ and ${ }^{* *} P<0.01$ versus cells transfected with C-miR or siCtrl in serum-free media

Although caspase-3 is a major executive effector of apoptosis, accumulating evidence recognizes caspase- 1 as another contributor to non-canonical apoptosis induced by homocysteine, inflammation, and serum deprivation. ${ }^{11,26,45}$ Caspase- 1 is generally activated by the formation of the NLRP3 inflammasome complex consisting of NLRP3, ASC, and procaspase-1. Although the NLRP3 inflammasome complex is essential for caspase-1-mediated maturation of IL- $1 \beta$ and IL- $18,{ }^{46}$ this complex also mediates pyroptosis via caspase- 1 activation. ${ }^{15}$ Indeed, caspase-1 activation through inflammasome formation plays an important role in homocysteineinduced endothelial dysfunction by inducing pyroptosis and apoptosis, ${ }^{11}$ likely by activating caspase-7, but not caspase-3. ${ }^{26}$ Similarly, our results showed that caspase- 1 activated caspase-7, but not caspase-3, in serum-deprived endothelial cells. NLRP3 inflammasome activity is positively regulated by ROS derived from mitochondria, ${ }^{12}$ and the ROS production can be elevated by Bim-dependent mitochondrial dysfunction. ${ }^{47}$ We found that decreased miR-101-3p in serumdeprived cells promoted mitochondrial ROS-mediated caspase-1 activation and apoptosis by upregulating Bim expression. However, serum deprivation had no effect on expression and maturation of $\mathrm{IL}-1 \beta$ and $\mathrm{IL}-18$, indicating that these cytokines are not involved in serum derivation-induced apoptosis. These results suggest that serum deprivation-induced apoptosis can be mediated by the miR-101-3p/Bim axis, which stimulates two distinct pathways, cytochrome $c$-mediated caspase-7/3 activation and ROS-dependent caspase-1/7 activation (Figure 9). Therefore, antioxidants may prevent apoptosis mediated by caspase- $1 / 7$, but not caspase-3.

Taken together, our results indicate that miR-101-3p downregulation is a key step in endothelial dysfunction induced by serum or growth factor withdrawal. We also provide evidence that miR-101-3p is an important determinant of endothelial function and vascular homeostasis in pathological conditions, such as trophic factor depletion, implicating miR-101-3p as a therapeutic target in cardiovascular disease, including atherosclerosis.

\section{Materials and Methods}

Materials. Cell culture media supplements and Lipofectamine RNAiMAX were purchased from Invitrogen Life Technologies (Invitrogen, Carlsbad, CA, USA). MitoSOX was purchased from Molecular Probes (Eugene, OR, USA). Antibodies against human Drosha, Dicer, Ago2, caspases-1/-3/-9, Bim, Bcl-2, COX2, NLRP3, ASC, IL-1 $\beta$, Mcl-1 and siRNAs against Bim, Dicer, Ago2, and ASC were purchased from Santa Cruz Biotechnology (Santa Cruz, CA, USA). Antibodies against human caspase-8, Bid, Bax, and cytochrome $c$ were purchased from BD Biosciences (San Jose, CA, USA). Antibody against human AMPK $\alpha$ was purchased from Cell Signaling Technology (Beverly, MA, USA). MiRNeasy Mini kit, miR-101-3p mimic, miScript SYBR Green PCR kit, and real-time PCR primers were purchased from Qiagen (Hilden, Germany). Caspase inhibitors and substrates were purchased from Alexis Corporation (San Diego, CA, USA). Other chemicals were purchased from Sigma (St. Louis, MO, USA).

Cell culture and treatment. HUVECs were cultured as previously described. $^{20}$ Cells were transfected with $100 \mathrm{nM}$ of control miR, miR-101-3p mimic, antagomiR-101-3p or siRNAs (100 nM) targeted to Bim, Dicer, Ago2, ASC using Lipofectamine RNAiMAX for $24 \mathrm{~h}$ and cultured with or without caspase inhibitors $(50 \mu \mathrm{M})$, Trolox $(10 \mu \mathrm{M})$ or Mito-TEMPO $(10 \mu \mathrm{M})$ in M199 supplemented 


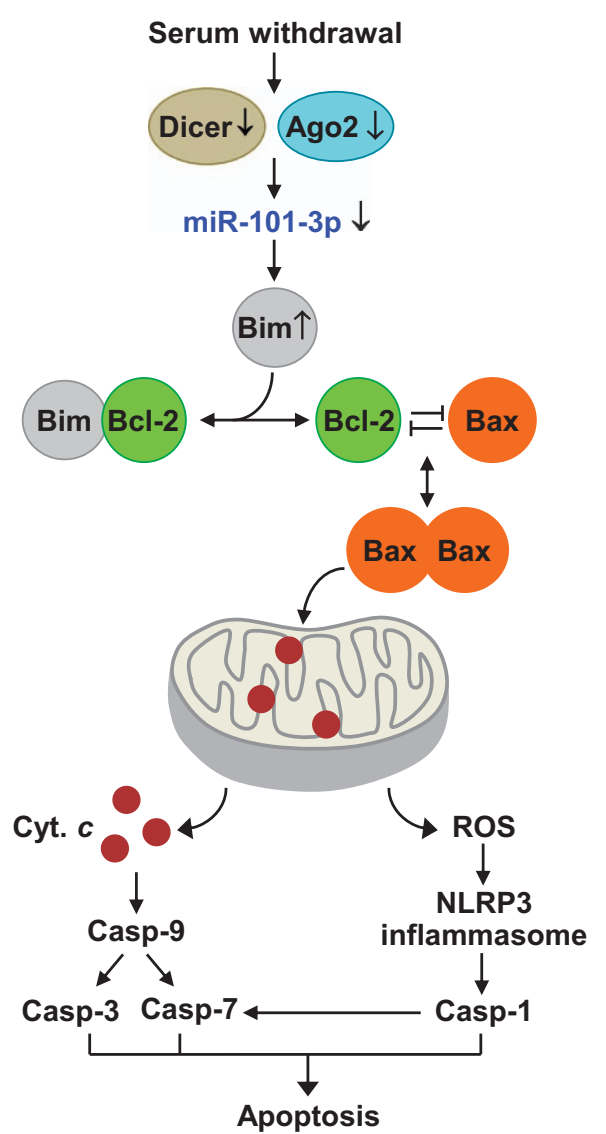

Figure 9 A schematic diagram showing the functional involvement of miR-101-3p in serum withdrawal-induced apoptosis by targeting Bim. Serum deprivation inhibits miR-101-3p biogenesis by downregulating Dicer and Ago2 expression, leading to increased Bim expression. Bim interacts with Bcl-2 to allow the release of Bax, which drives cytochrome $c$ release and ROS generation from mitochondria. Both events induce intrinsic apoptosis via caspases-9/7/3 activation and inflammasome-mediated caspase-1/7 activation, respectively

with 0 or $5 \%$ FBS for $8-30 \mathrm{~h}$. The cells were used for further analyses. In addition, tumor cells (MCF-7, HeLa, and HCT116) were also cultured in RPMI medium supplemented with $0 \%$ or $5 \%$ FBS.

Polymerase chain reaction. Cells were cultured in serum-free or $5 \%$ FBS-supplemented media containing $50 \mu \mathrm{M}$ z-VAD-fmk for $16 \mathrm{~h}$, and miRNAs were isolated using a miRNeasy mini kit according to manufacturers' protocols. CDNA for determining miRNAs was synthesized from $1 \mu \mathrm{g}$ of miRNAs using a miScript II RT kit. Levels of precursor and mature miR-101-3p were determined by qRT-PCR using a miScript SYBR Green PCR kit with miR-101-3p-specific and universal primers (Qiagen) as previously described. ${ }^{20}$ Levels of Drosha, Dicer, Ago2, Bim, Mcl-1, AMPK and cytokine mRNAs were determined by HiPi Real-Time PCR 2x Master Mix (SYBR Green+ROX) (Elpis, Daejeon, Korea) with Rotor-Gene Q (Qiagen) using targetspecific primers. The primers used in this study are listed in Supplementary Table S1.

Western blot analysis. Western blot analysis for target proteins in whole-cell lysates and in cytosolic and mitochondrial fractions was performed as previously described. $^{20}$

Cell viability assay. Cell viability was evaluated by 3-[4,5-cimethylthiazol-2-yl]2,5-diphenyl tetrazolium bromide (MTT; Sigma-Aldrich, St. Louis, MO, USA) assay. Cells were transfected with miR-101-3p mimic or Bim siRNA using Lipofectamine RNAiMAX and cultured for $30 \mathrm{~h}$, followed by incubation with MTT solution $(1 \mathrm{mg} / \mathrm{ml})$ for $2 \mathrm{~h}$ at $37^{\circ} \mathrm{C}$. Cell viability was determined by measuring absorbance at $550 \mathrm{~nm}$ using a microplate reader.
TUNEL assay. Cells were transfected with control miRNA (C-miR) or miR-101$3 p$ mimic and cultured in serum-free or 5\% FBS-supplemented media for $24 \mathrm{~h}$. Coverslips with adherent cells were fixed in $4 \%$ paraformaldehyde for $15 \mathrm{~min}$ at room temperature. DNA fragmentation, which indicates apoptosis, was analyzed according to the manufacturer's instructions using terminal deoxynucleotidyl transferase with peroxide-12-UTP nick-end labeling (TUNEL) (Roche Molecular Biochemicals, Indianapolis, IN, USA). Cells were counterstained with DAPI, mounted cell side down on a microscope slide, and analyzed by confocal microscopy. TUNEL-positive cells appeared red.

Annexin V-FITC staining. Cells were transfected with C-miR, miR-101-3p mimic or Bim siRNA and cultured in serum-free or $5 \%$ FBS-supplemented media for $24 \mathrm{~h}$. Apoptosis was determined using Annexin V-FITC/PI according to the manufacturer's instructions (BD Biosciences, San Jose, CA, USA). Ten thousand cells were counted for three independent experiments. Apoptosis was evaluated by measuring the total amount of Annexin $\mathrm{V}^{+} / \mathrm{Pl}^{-}$cells and Annexin $\mathrm{V}^{+} / \mathrm{PI}^{+}$cells.

Caspase activity assay. Cells were transfected with C-miR or miR-101-3p mimic and cultured with or without $50 \mu \mathrm{M}$ of Z-VAD-fmk (Z), Ac-IETD-cho (I), ACDEVD-cho (D), Ac-LEHD-cho (L), or Ac-YVAD-cho $(Y)$ in serum-free or $5 \%$ FBSsupplemented media for $24 \mathrm{~h}$. Caspase activity was determined by measuring proteolytic cleavage of the chromogenic substrates, Ac-IETD-pNA (caspase-8-like activity), Ac-LEHD-pNA (caspase-9-like activity), Ac-DEVD-pNA (caspase-7/3-like activity), or Ac-YVAD-pNA (caspase-1-like activity) as described previously. ${ }^{47}$ One unit of caspase activity is defined as an increase in absorbance of 0.1 at $405 \mathrm{~nm}$ per $\mathrm{mg}$ protein per hour.

Luciferase assay. Cells transfected with C-miR or miR-101-3p mimic or psiCHECK-2/Bim 3'-UTR (wild-type or mutant) were cultured in serum-free or $5 \%$ FBS-supplemented media containing $50 \mu \mathrm{M}$ Z-VAD-fmk for $16 \mathrm{~h}$. The $3^{\prime} \mathrm{UTR}(\sim 0.7 \mathrm{~kb})$ of Bim was prepared from human genomic DNA by PCR using the following wild-type primers, 5'-ATTCTCGAGTGTACTCACGTGCCAGTC-3' (forward) and 5'-TTAGCGGCC GCACTCACAATATATACATT-3' (reverse). The $3^{\prime} \mathrm{UTR}(\sim 0.7 \mathrm{~kb})$ of Bim was prepared from wild-type by PCR using the following mutant primers, $5^{\prime}$-TGACTGGATGTCTC TGGAATTATGTATCTGGTTATCA-3'(forward) and 5'-TGATAACCAGATACATAAATTCC AGAGACATCCAGTCA-3' (reverse). The PCR products were ligated at the Xhol and Noth sites of psiCHECK-2 vector (Promega, Madison, WI, USA). Reporter activity was assayed using a dual-luciferase report assay kit (Promega).

Immunoprecipitation. Cells transfected with C-miR, miR-101-3p mimic or Bim siRNA were cultured in serum-free or $5 \%$ FBS-supplemented media for $12 \mathrm{~h}$. Cell lysates (2 mg of protein) were incubated with an antibody $(1 \mu \mathrm{g})$ for $\mathrm{Bcl}-2$ or ASC in RIPA buffer with gentle agitation overnight at $4^{\circ} \mathrm{C}$. The lysates were then incubated with protein G-Sepharose bead slurry (100 $\mu$, Millipore, Merck KGaA, Darmstadt, Germany), and immune complexes were collected by centrifugation. Immunoprecipitates were separated by SDS-gel electrophoresis, followed by western blot analysis using the indicated antibodies.

Measurement of MMP. Cells transfected with C-miR, miR-101-3p mimic or Bim siRNA were cultured in serum-free or $5 \%$ FBS-supplemented media for $12 \mathrm{~h}$. MMP was monitored by confocal microscopy. Cells were stained with $2 \mu \mathrm{mol} / / \mathrm{l}$ of JC-1 (Molecular Probes) for $30 \mathrm{~min}$ at $37^{\circ} \mathrm{C}$. Fluorescence intensities were determined at the single-cell level by confocal microscopy. Data are expressed as a normalized ratio of the fluorescence intensity of the monomeric form (low MMP, green) to the JC-1-aggregate form (high MMP, red).

Measurement of mitochondrial ROS production. Mitochondrial ROS levels were measured using the mitochondrial superoxide indicator MitoSOX Red. Cells transfected with C-miR, miR-101-3p mimic or Bim siRNA were cultured in serum-free or $5 \%$ FBS-supplemented media for $12 \mathrm{~h}$. Cells were loaded with MitoSOX Red $(5 \mu \mathrm{M})$ for $10 \mathrm{~min}$. After being washed with PBS, the accumulation of red fluorescence (excitation $510 \mathrm{~nm}$, emission $580 \mathrm{~nm}$ ) was determined by confocal microscopy.

Statistical analysis. Quantitative data are expressed as the mean \pm S.D. of at least three separate experiments. Statistical significance was determined using either one-way ANOVA or unpaired Student's $t$-test, depending on the number of experimental groups analyzed. Significance was established at $P<0.05$. 


\section{Conflict of Interest}

The authors declare no conflict of interest.

Acknowledgements. This work was supported by the National Research Foundation of Korea (NRF) grant funded by the Korea government (MSIP) (2013M3A9B6046367 and 2016M3A9B6903103).

1. Hadi HA, Carr CS, Al Suwaidi J. Endothelial dysfunction: cardiovascular risk factors, therapy, and outcome. Vasc Health Risk Manag 2005; 1: 183-198.

2. Deanfield JE, Halcox JP, Rabelink TJ. Endothelial function and dysfunction: testing and clinical relevance. Circulation 2007; 115: 1285-1295.

3. Kroemer G, El-Deiry WS, Golstein P, Peter ME, Vaux D, Vandenabeele P et al. Classification of cell death: recommendations of the Nomenclature Committee on Cell Death. Cell Death Differ 2005; 2: 1463-1467.

4. Galluzzi L, Vitale I, Abrams JM, Alnemri ES, Baehrecke EH, Blagosklonny MV et al. Molecular definitions of cell death subroutines: recommendations of the Nomenclature Committee on Cell Death 2012. Cell Death Differ 2012; 19: 107-120.

5. de Vries EG, Gietema JA, de Jong S. Tumor necrosis factor-related apoptosis-inducing ligand pathway and its therapeutic implications. Clin Cancer Res 2006; 12: 2390-2393.

6. McClintock DS, Santore MT, Lee VY, Brunelle J, Budinger GR, Zong WX et al. Bcl-2 family members and functional electron transport chain regulate oxygen deprivation-induced cell death. Mol Cell Biol 2002; 22: 94-104.

7. Gross A, McDonnell JM, Korsmeyer SJ. BCL-2 family members and the mitochondria in apoptosis. Genes Dev 1999; 13: 1899-1911.

8. Delbridge AR, Strasser A. The BCL-2 protein family, BH3-mimetics and cancer therapy. Cell Death Differ 2015; 22: 1071-1080.

9. Czabotar PE, Lessene G, Strasser A, Adams JM. Control of apoptosis by the BCL-2 protein family: implications for physiology and therapy. Nat Rev Mol Cell Biol 2014; 15: 49-63.

10. Wang S, Park S, Fei P, Sorenson CM. Bim is responsible for the inherent sensitivity of the developing retinal vasculature to hyperoxia. Dev Biol 2011; 349: 296-309.

11. Xi H, Zhang Y, Xu Y, Yang WY, Jiang X, Sha $X$ et al. Caspase-1 inflammasome activation mediates homocysteine-induced Pyrop-apoptosis in endothelial cells. Circ Res 2016; 118: $1525-1539$

12. Zhou R, Yazdi AS, Menu P, Tschopp J. A role for mitochondria in NLRP3 inflammasome activation. Nature 2011; 469: 221-225.

13. Xi H, Zhang $Y, X u Y$, Yang WY, Jiang $X$, Sha $X$ et al. Caspase-1 inflammasome activation mediates homocysteine-induced pyrop apoptosis in endothelial cells. Circ Res 2016; 118 : 1525-1539.

14. Bartel DP. MicroRNAs: target recognition and regulatory functions. Cell 2009; 136: 215-233

15. Callis TE, Pandya K, Seok HY, Tang RH, Tatsuguchi M, Huang ZP et al. MicroRNA-208a is a regulator of cardiac hypertrophy and conduction in mice. J Clin Invest 2009; 119: 2772-2786.

16. Quiat D, Olson EN. MicroRNAs in cardiovascular disease: from pathogenesis to prevention and treatment. J Clin Invest 2013; 123: 11-18.

17. Veronese A, Lupini L, Consiglio J, Visone R, Ferracin M, Fornari F et al. Oncogenic role of miR-483-3p at the IGF2/483 locus. Cancer Res 2010; 70: 3140-3149.

18. Zhang CZ, Zhang JX, Zhang AL, Shi ZD, Han L, Jia ZF et al. MiR-221 and miR-222 target PUMA to induce cell survival in glioblastoma. Mol Cancer 2010; 9: 229.

19. Li Y, Choi PS, Casey SC, Dill DL, Felsher DW. MYC through miR-17-92 suppresses specific target genes to maintain survival, autonomous proliferation, and a neoplastic state. Cancer Cell 2014; 26: 262-272.

20. Kim JH, Lee KS, Lee DK, Kim J, Kwak SN, Ha KS et al. Hypoxia-responsive microRNA-101 promotes angiogenesis via heme oxygenase-1/vascular endothelial growth factor axis by targeting cullin 3. Antioxid Redox Signal 2014; 21: 2469-2482.

21. Winter J, Jung S, Keller S, Gregory RI, Diederichs S. Many roads to maturity: microRNA biogenesis pathways and their regulation. Nat Cell Biol 2009; 11: 228-234.

22. Hawkins SM, Andreu-Vieyra CV, Kim TH, Jeong JW, Hodgson MC, Chen R et al. Dysregulation of uterine signaling pathways in progesterone receptor-Cre knockout of dicer. Mol Endocrinol 2012; 26: 1552-1566

23. Hogg N, Browning J, Howard T, Winterford C, Fitzpatrick D, Gobé G. Apoptosis in vascula endothelial cells caused by serum deprivation, oxidative stress and transforming growth factor- $\beta$. Endothelium 1999; 7: 35-49.

24. Cotter TG. Apoptosis and cancer: the genesis of a research field. Nat Rev Cancer 2009; 9 501-507.

25. Sollberger G, Strittmatter GE, Grossi S, Garstkiewicz M, Auf dem Keller U, French LE et a Caspase-1 activity is required for UVB-induced apoptosis of human keratinocytes. $J$ Invest Dermatol 2015; 135: 1395-1404

26. Lamkanfi M, Kanneganti TD, Van Damme P, Vanden Berghe T, Vanoverberghe I, Vandekerckhove $\mathrm{J}$ et al. Targeted peptidecentric proteomics reveals caspase-7 as a substrate of the caspase-1 inflammasomes. Mol Cell Proteomics 2008; 7: 2350-2363.
27. Zhang JG, Guo JF, Liu DL, Liu Q, Wang JJ. MicroRNA-101 exerts tumor-suppressive functions in non-small cell lung cancer through directly targeting enhancer of zeste homolog 2. J Thorac Oncol 2011; 6: 671-678.

28. Asada S, Takahashi T, Isodono K, Adachi A, Imoto H, Ogata T et al. Downregulation of Dicer expression by serum withdrawal sensitizes human endothelial cells to apoptosis. Am J Physiol Heart Circ Physiol 2008; 295: H2512-H2521.

29. Peterson QP, Goode DR, West DC, Botham RC, Hergenrother PJ. Preparation of the caspase3/7 substrate Ac-DEVD-pNA by solution-phase peptide synthesis. Nat Protoc 2010; 5: 294-302.

30. Gibbings D, Mostowy S, Jay F, Schwab Y, Cossart P, Voinnet O. Selective autophagy degrades DICER and AGO2 and regulates miRNA activity. Nat Cell Biol 2012; 14: 1314-1321.

31. Liu X, Tang H, Chen J, Song C, Yang L, Liu P et al. MicroRNA-101 inhibits cell progression and increases paclitaxel sensitivity by suppressing MCL-1 expression in human triplenegative breast cancer. Oncotarget 2015; 6: 20070-20083.

32. Liu $P$, Ye F, Xie X, Li X, Tang H, Li S et al. mir-101-3p is a key regulator of tumor metabolism in triple negative breast cancer targeting AMPK. Oncotarget 2016; 7: 35188-35198.

33. Koenig MN, Naik E, Rohrbeck L, Herold MJ, Trounson E, Bouillet P et al. Pro apoptotic BIM is an essential initiator of physiological endothelial cell death independent of regulation by FOXO3. Cell Death Differ 2014; 21: 1687-1695.

34. Kong PJ, Kil MO, Lee H, Kim SS, Johnson GV, Chun W. Increased expression of Bim contributes to the potentiation of serum deprivation-induced apoptotic cell death in Huntington's disease knock-in striatal cell line. Neurol Res 2009; 31: 77-83.

35. Mojsa B, Mora S, Bossowski JP, Lassot I, Desagher S. Control of neuronal apoptosis by reciprocal regulation of NFATc3 and Trim17. Cell Death Differ 2015; 22: 274-286.

36. Ventura A, Young AG, Winslow MM, Lintault L, Meissner A, Erkeland SJ et al. Targeted deletion reveals essential and overlapping functions of the miR-17 through 92 family of miRNA clusters. Cell 2008; 132: 875-886.

37. Pernaute B, Spruce T, Smith KM, Sánchez-Nieto JM, Manzanares M, Cobb B et al. MicroRNAs control the apoptotic threshold in primed pluripotent stem cells through regulation of BIM. Genes Dev 2014; 28: 1873-1878.

38. Bu Q, Fang Y, Cao Y, Chen Q, Liu Y. Enforced expression of miR-101 enhances cisplatin sensitivity in human bladder cancer cells by modulating the cyclooxygenase-2 pathway. Mol Med Rep 2014; 10: 2203-2209.

39. Zhao X, Wang K, Hu F, Qian C, Guan H, Feng K et al. MicroRNA-101 protects cardiac fibroblasts from hypoxia-induced apoptosis via inhibition of the TGF- $\beta$ signaling pathway. Int J Biochem Cell Biol 2015; 65: 155-164.

40. Crow MT, Mani K, Nam YJ, Kitsis RN. The mitochondrial death pathway and cardiac myocyte apoptosis. Circ Res 2004; 95: 957-970.

41. Kim YM, Kim JH, Kwon HM, Lee DH, Won MH, Kwon YG et al. Korean Red Ginseng protects endothelial cells from serum-deprived apoptosis by regulating $\mathrm{Bcl}-2$ family protein dynamics and caspase S-nitrosylation. J Ginseng Res 2013; 37: 413-424.

42. Min JK, Kim JH, Cho YL, Maeng YS, Lee SJ, Pyun BJ et al. 20(S)-Ginsenoside Rg3 prevents endothelial cell apoptosis via inhibition of a mitochondrial caspase pathway. Biochem Biophys Res Commun 2006; 349: 987-994

43. Liang M, Russell G, Hulley PA. Bim, Bak, and Bax regulate osteoblast survival. J Bone Miner Res 2008; 23: 610-620.

44. Naik E, O'Reilly LA, Asselin-Labat ML, Merino D, Lin A, Cook M et al. Destruction of tumor vasculature and abated tumor growth upon VEGF blockade is driven by proapoptotic protein Bim in endothelial cells. J Exp Med 2011; 208: 1351-1358.

45. Kaushal V1, Dye R, Pakavathkumar P, Foveau B, Flores J, Hyman B et al. Neuronal NLRP1 inflammasome activation of Caspase-1 coordinately regulates inflammatory interleukin-1. beta production and axonal degeneration-associated Caspase-6 activation. Cell Death Diffe 2015: 22: 1676-1686.

46. Martinon F, Burns K, Tschopp J. The inflammasome: a molecular platform triggering activation of inflammatory caspases and processing of prolL- $\beta$. Mol Cell 2002; 10: 417-426.

47. Hagenbuchner J, Ausserlechner MJ. Mitochondria and FOXO3: breath or die. Front Physiol 2013; 4 : 147.

(c) (i) Cell Death and Disease is an open-access journal published by Nature Publishing Group. This work is licensed under a Creative Commons Attribution 4.0 International License. The images or other third party material in this article are included in the article's Creative Commons license, unless indicated otherwise in the credit line; if the material is not included under the Creative Commons license, users will need to obtain permission from the license holder to reproduce the material. To view a copy of this license, visit http://creativecommons.org/licenses/by/4.0/

(C) The Author(s) 2017 